\title{
Cystic Fibrosis: Fighting Together Against Coronavirus Infection
}

\author{
Sara Manti, Giuseppe Fabio Parisi ${ }^{\star}$, Maria Papale, Enza Mulè, Donatella Aloisio, \\ Novella Rotolo and Salvatore Leonardi
}

Pediatric Respiratory Unit, Department of Clinical and Experimental Medicine, University of Catania, Catania, Italy

Keywords: cystic fibrosis, COVID 19, coronavirus, SARS-CoV-2, recommandation

\section{INTRODUCTION}

In a critical moment like this in which all world population is hard fighting with limited weapons against coronavirus (COVID-19) infection, we strongly feel the duty and the need to provide real help and clear information to people with underlying health conditions, such as cystic fibrosis (CF), to protect themselves and ones living with patients with CF as best as possible.

To achieve this goal, we briefly summarized the current state of knowledge on COVID-19

OPEN ACCESS

Edited by:

Mehdi Mirsaeidi,

University of Miami, United States

Reviewed by:

Isabelle Sermet-Gaudelus, Institut National de la Santé et de la

Recherche Médicale (INSERM), France

Steven M. Rowe,

University of Alabama at Birmingham,

United States

Carlos Emilio Levy,

State University of Campinas, Brazil

${ }^{*}$ Correspondence:

Giuseppe Fabio Parisi

giuseppeparisi88@hotmail.it

Specialty section:

This article was submitted to

Pulmonary Medicine

a section of the journal

Frontiers in Medicine

Received: 06 April 2020

Accepted: 28 May 2020

Published: 09 June 2020

Citation:

Manti S, Parisi GF, Papale M, Mulè E,

Aloisio $D$, Rotolo $N$ and Leonardi $S$

(2020) Cystic Fibrosis: Fighting

Together Against Coronavirus

Infection. Front. Med. 7:307.

doi: 10.3389/fmed.2020.00307 infection in patients affected by CF. Moreover, we provided a simple flow-chart to summarize the recommendations suggested for patients at higher risk of severe illness, such as people affected by CF (Figure 1).

\section{CYSTIC FIBROSIS AND VIRAL INFECTIONS}

Respiratory viral infections are common events throughout human life; however, when they occur in patients with chronic and/or underlying health conditions, their impact can become dramatic (1).

Among people with CF, respiratory viruses are associated with prolonged respiratory illness and show a clear association with pulmonary exacerbations, lung function decline, and risk of death $(1,2)$. Although the impact of respiratory viral infections on CF lung disease history is poorly understood, several mechanisms have been hypothesized to play a crucial role (3). The inflammation that characterizes the lower respiratory tract in $\mathrm{CF}$ is not primarily started by the genetic defect rather than viral infections that, already present in almost $40 \%$ of infants with CF at 3 months of age, impair the specific anti-bacterial defense, increase the adherence of bacteria to the mucous membrane, impact negatively nitric oxide synthase 2 (NOS2) activity, and, enhancing the pro-inflammatory cytokine production [interleukin (IL)-6 and IL-8], affect the immune defense in the human airway, resulting in severe respiratory illness in CF patients (4).

Specifically, CFTR deficiency results in changes in osmotic pressures and electro-neutrality which cause excessive sodium and water absorption, dehydration of the airway surface liquid and mucus layer as well as changing in $\mathrm{pH}$ airway surface liquid, favoring chronic retention of pathogens and a secondary inflammatory response (5). The increase in vesicular $\mathrm{pH}$ of cells with CF transmembrane conductance regulator (CFTR) deficiency seems to cause the inhibition of acid ceramidase resulting in the accumulation of lung epithelial ceramide that, in turn, increases cell death, stimulates bacterial binding to extracellular DNA, and initiate IL-1ß and chemokine synthesis (6). Moreover, the extensive plugging of the small airways by purulent mucus leads to a decrease in oxygen tension, which, in turn, can affect the host anti-bacterial defenses and favor bacterial growth (7). Another impaired mechanism described in cells of patients with CF is an abnormally high arachidonic acid to docosahexaenoic acid (AA/DHA) ratio which is associated with an increased inflammatory response (8). 


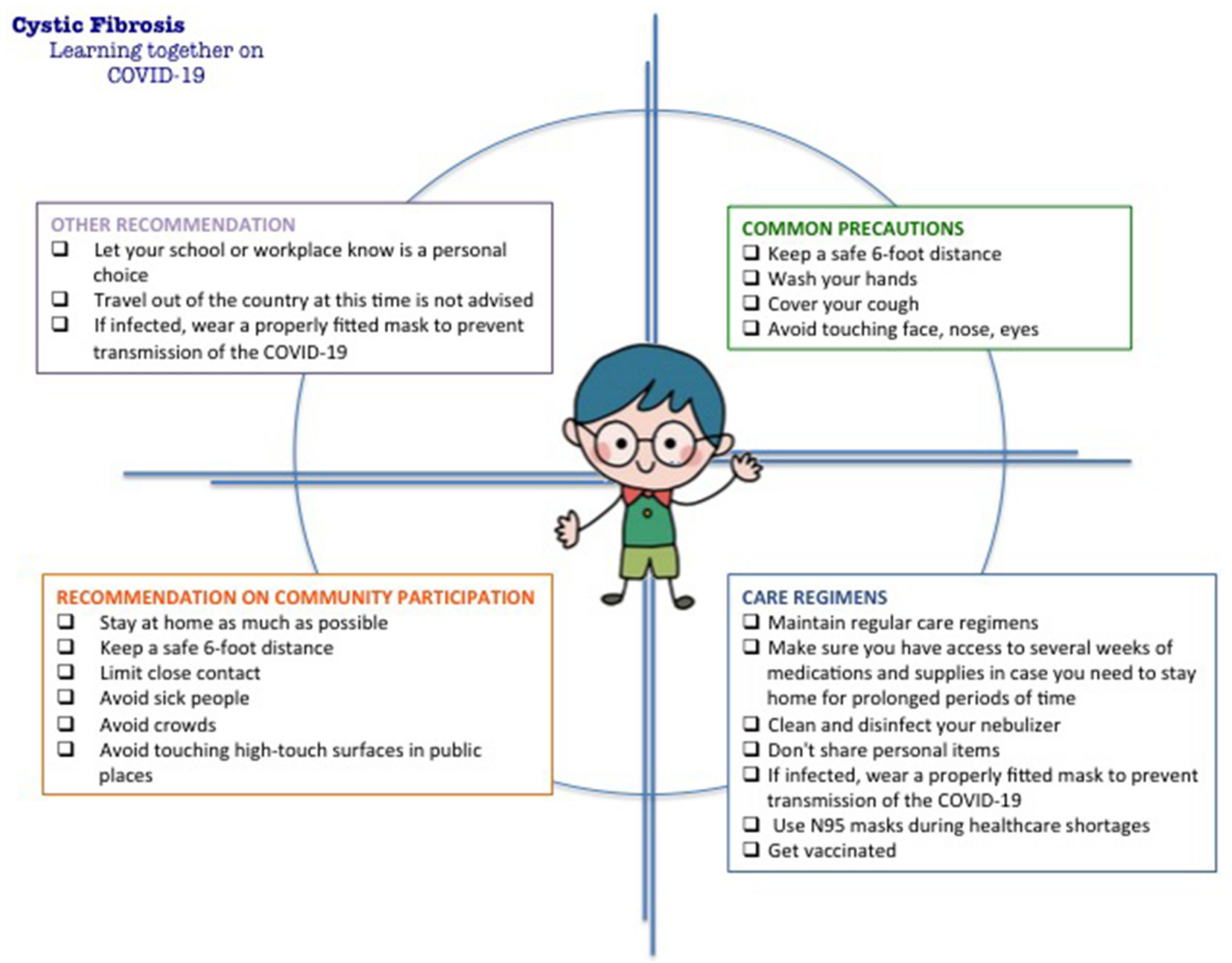

FIGURE 1 | Suggested recommendations regarding the coronavirus (COVID-19) infection for patients at higher risk of severe illness.

The onset and persistence of inflammation in CF are critically important in host-pathogen interactions. Whether inflammation follows or rather precedes infection is still under debate but, undoubtedly, the inflammation of the airways is one of the key elements of the pathogenesis of the infections in $\mathrm{CF}$ patients. As a result of chronic inflammation, immune cells show multiple defects: neutrophils do not transport halide in the phagolysosome, thus, they are not efficient into oxidative killing (9); macrophages show a delayed phagolysosomal fusion and bacterial clearance as well as an enhanced toll-like receptor (TLR)4-dependent response to lipopolysaccharides (LPS) (10); naïve $\mathrm{T}$ lymphocytes are predisposed to differentiate toward a $\mathrm{T}$ helper (Th)17 phenotype (11). In parallel to all the above-mentioned mechanisms, the host factors also allow an increased virus replication. An impaired activation both of signal transducer and activator of transcription 1 (STAT 1) and NOS2, fundamental components of interferon (IFN)$y$-mediated antiviral defense, increases the virus load and supports the severity of virus disease in CF (12). On the other hand, an exaggerated activation of the transcriptional regulatory complex nuclear factor $(\mathrm{NF})-\kappa \mathrm{B}$ results in an increased production of proinflammatory cytokines (13). Therefore, it appears as in the context of the severity of pre-existing pulmonary and comorbidity CF disease, a lesser antiviral and greater inflammatory response are likely to contribute to severe respiratory illnesses of CF patients with viral infections, inducing and/or precipitating CF exacerbations (14).

Whether, historically, bacteria have been the predominant causes for respiratory exacerbations, these findings highlight as also viral agents can lead to clinical deterioration and, subsequently, morbidity, and mortality. CF pulmonary exacerbation rate is associated with the Influenza $A$ and $B$ viruses, Respiratory Syncytial Virus (RSV), Parainfluenza virus types 1 to 4, Rhinovirus, Metapneumovirus, and Adenovirus (15-18).

\section{COVID-19 AND CYSTIC FIBROSIS}

Unlike human rhinovirus, consistently the most common respiratory virus affecting patients with $\mathrm{CF}$, coronavirus $(\mathrm{CoV})$ is an uncommon viral agent in this population (19-21). Moreover, in line with these findings, authors revealed that human $\mathrm{CoV}$ $(\mathrm{HCoV})$ seem to have comparably little impact both on the rate 
of respiratory exacerbations and course of $\mathrm{CF}$, with the exception for NL63 $(1,4)$. In this regard, Authors reported that HCoV seemed to have the same clinical impact of human Rhinovirus (HRV) in children with CF (20). Epidemiological findings reveal that $\mathrm{HCoV}$ is the second most prevalent respiratory virus in a 6month winter period after HRV, and, these data are comparable to a cohort of age-matched healthy children (21). Moreover, in a study performed during a whole year period also including the summer season, Authors detected $\mathrm{HCoV}$ in a percentage of $0.8 \%$, suggesting the marginal role of this virus in patients with CF (21).

Unfortunately, a new member of the large family of CoV, CoVID-19, is causing significant concern worldwide. Given the "young age" of the infection, specific literature data on CF patients are still not available but evidence has clearly assessed that people with underlying health conditions, including CF, seem to be a major risk of COVID-19-mediated serious illness. Several possible explanations for the severe clinical impact of SARS-CoV-2 virus in CF patients have been hypothesized. Similarly to HCoV-NL63, SARS-CoV-2 virus uses the angiotensin-converting enzyme-2 (ACE-2) as the main pathway for attachment and entry in the cell. Generally, following infection, a critical reduction in ACE-2 expression on the cell surfaces occurs; however, the rate of this down-regulation appears lower in CF patients when compared to patients not affected by CF (22). ACE-2 down-regulation is associated with an increase in the inflammatory response against the virus, thus, this event may be one of the determinants of severity of COVID-19 in CF patients (22). Moreover, genetic polymorphisms associated with an increase in ACE-2 expression have been related to a worse lung disease in CF patients (23). Lastly, the impact of COVID-19 is also associated with the baseline lung function of the CF patient, therefore, it is possible that subjects with severe lung disease are at higher risk to present an exacerbation, and, consequently, are more likely to develop severe COVID-19 form (24). Currently, to the best of our knowledge, COVID19 has been confirmed in 58 patients with CF (age range, 628 years) (25). Ten of them were notified in Italy, and three of whom have been hospitalized. All infected patients were living in the endemic area, Lombardia, and acquired the infection from family members. Five patients with CF have been reported to have SARS-CoV-2 infection in Germany. Three patients with CF were also notified in Spain and one of them was transplanted (26). More detailed demographic and clinical findings of 40 out of 58 patients were collected only by eight countries including Australia, Canada, France, Ireland, Netherlands, New Zealand, United Kingdom (UK), and United States (US) (27). Of the 40 cases, 31 (78\%) were symptomatic for SARS-CoV-2 at presentation, with $24(60 \%)$ having a fever. The median age was 33 years (age range, 15-59 years). Thirty-eight percentage had CF-related diabetes mellitus (CFRD) and 70\% were reported to have chronic bacterial pulmonary infection, of which $71 \%$ included Pseudomonas aeruginosa. One patient was pregnant and she was recovered, delivering a healthy baby. Eleven patients have been from post-lung transplant patients, who were on average 6 years post their transplant. Twenty-five $(63 \%)$ patients were treated with new antibiotics: 10 subjects with oral antibiotics and 17 patients intravenous (IV) antibiotic treatment. Two people were receiving both oral and IV antibiotics. Fourteen people were reported as using CFTR modulators, 13 (33\%) patients required oxygen, and only 1 out of 40 patients required invasive ventilatory support. Four out of 40 patients were admitted to Intensive Care Unit (ICU), and 3 of all them required oxygen. Twenty-eight out of 40 cases have been reported as clinically recovered from SARS-CoV-2, and no deaths were reported (27). No specific data are available about the incidence and outcomes within the pediatric CF population, and only one child affected by COVID-19 has been notified. A case of COVID-19 in a 1-month-old infant with CF has been reported; the patient presented with asymptomatic infection, despite his underlying condition (28). In summary, the above-mentioned findings show good recovery from COVID-19 even if in a heterogeneous CF cohort. Apparently, the disease course does not seem to differ from the general population, but the available epidemiological data are too small to draw conclusions. Dry cough, malaise, and fever are quite distinct from the symptoms of $\mathrm{CF}$, thus, it is reasonable to hypothesize that patients with $\mathrm{CF}$ are recognizable, on the other hand, we cannot exclude that mild forms of COVID-19 may be mistaken for the common spectrum of CF symptoms. Obviously, taking into account the sparse available evidence, any conclusion can be reached about the incidence of COVID-19 both in adult and children with CF, and further and collaborative studies are required for a complete understanding of SARS- CoV2 infection impact on patients with CF. Moreover, people affected by CF should continue to strictly follow public health advice to protect themselves from COVID-19.

Although early and partial, these findings are encouraging and supporting the good job done to avoid SARS-CoV-19 infection. Compared to SARS-CoV-2 infection, H1N1 virus caused significant morbidity in patients with $\mathrm{CF}$ and resulting in respiratory deterioration, mechanical ventilation, and even death (29). At present, it is not possible to identify factors that might be protective, for example, use of long-term antibiotic therapy such as azithromycin, minimizing social contacts and self-isolation, cancellation of routine clinic appointments and procedures (respiratory function testing and bronchoscopy) to prevent unnecessary hospital visits and viral spread, and self-monitoring.

\section{DISCUSSION}

In absence of specific recommendations, we strongly encourage patients with CF to refer to the Centers for Disease Control and Prevention (CDC) guideline for people at higher risk for severe illness, defined as "older adults and people who have severe chronic medical conditions (e.g., heart, lung, or kidney

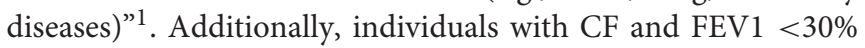
predicted with a predicted median survival longer than 5 years should not have a lower priority for intensive care (30).

To slow the spread and reduce the impact of the disease the following actions are recommended: (i) stay at home as

\footnotetext{
${ }^{1}$ https://www.ecdc.europa.eu/sites/default/files/documents/RRA-seventhupdate-Outbreak-of-coronavirus-disease-COVID-19.pdf
} 
much as possible; (ii) make sure to have access to medications and supplies at home for prolonged periods of time; (iii) take everyday precautions including keeping a safe 6-foot distance, limit close contact, avoid sick people and avoid crowds; wash hands often, avoid touching face, nose, eyes, avoid touching hightouch surfaces in public places; cover cough; clean and disinfect the nebulizer; get vaccinations.

\section{People With CF Should Maintain Their Regular Care Regimens}

Let school or workplace is a personal decision. Travel out of the country at this time is not advised. Commonly available surgical and cloth masks have not been shown to protect against COVID19; however, people who have or are likely to have SARS-CoV-2 infection will need to wear a mask to help control the spread of the virus to others. Moreover, wearing a properly fitted facemask (surgical or non-medical) it is also recommended when a healthy person leaves home, especially if they will be in contact with

\section{REFERENCES}

1. Flight W, Jones A. The diagnosis and management of respiratory viral infections in cystic fibrosis. Expert Rev Respir Med. (2017) 11:2217. doi: 10.1080/17476348.2017.1288102

2. Hoek RA, Paats MS, Pas SD, Bakker M, Hoogsteden HC, Boucher $\mathrm{CA}$, et al. Incidence of viral respiratory pathogens causing exacerbations in adult cystic fibrosis patients. Scand J Infect Dis. (2013) 45:659. doi: 10.3109/00365548.2012.708942

3. Eymery M, Morfin F, Doleans-Jordheim A, Perceval M, Ohlmann C, Mainguy C, et al. Viral respiratory tract infections in young children with cystic fibrosis: a prospective full-year seasonal study. Virol J. (2019) 16:111. doi: 10.1186/s12985-019-1208-7

4. Frickmann H, Jungblut S, Hirche TO, Groß U, Kuhns M, Zautner AE. Spectrum of viral infections in patients with cystic fibrosis. Eur J Microbiol Immunol. (2012) 2:161-75. doi: 10.1556/EuJMI.2.2012.3.1

5. Button B, Cai LH, Ehre C, Kesimer M, Hill DB, Sheehan JK, et al. A periciliary brush promotes the lung health by separating the mucus layer from airway epithelia. Science. (2012) 337:937-41. doi: 10.1126/science.1223012

6. Becker KA, Riethmüller J, Zhang Y, Gulbins E. The role of sphingolipids and ceramide in pulmonary inflammation in cystic fibrosis. Open Respir Med J. (2010) 4:39-47. doi: 10.2174/1874306401004010039

7. Stoltz DA, Meyerholz DK, Pezzulo AA, Ramachandran S, Rogan MP, Davis GJ, et al. Cystic fibrosis pigs develop lung disease and exhibit defective bacterial eradication at birth. Sci Transl Med. (2010) 2:29ra31. doi: 10.1126/scitranslmed.3000928

8. Freedman SD, Blanco PG, Zaman MM, Shea JC, Ollero M, Hopper IK, et al. Association of cystic fibrosis with abnormalities in fatty acid metabolism. $N$ Engl J Med. (2004) 350:560-9. doi: 10.1056/NEJMoa021218

9. Painter RG, Marrero L, Lombard GA, Valentine VG, Nauseef WM, Wang G. CFTR-mediated halide transport in phagosomes of human neutrophils. J Leukoc Biol. (2010) 87:933-42. doi: 10.1189/jlb.1009655

10. Lamothe J, Valvano MA. Burkholderia cenocepacia-induced delay of acidification and phagolysosomal fusion in cystic fibrosis transmembrane conductance regulator (CFTR)-defective macrophages. Microbiology. (2008) 154:3825-34. doi: 10.1099/mic.0.2008/023200-0

11. Kushwah R, Gagnon S, Sweezey NB. Intrinsic predisposition of naïve cystic fibrosis T cells to differentiate towards a Th17 phenotype. Respir Res. (2013) 14:138. doi: 10.1186/1465-9921-14-138

12. Zheng S, De BP, Choudhary S, Comhair SA, Goggans T, Slee $\mathrm{R}$, et al. Impaired innate host defense causes susceptibility to respiratory virus infections in cystic fibrosis. Immunity. (2003) 18:619-30. doi: 10.1016/S1074-7613(03)00114-6 other people (30). All these recommendations are summarized in Figure 1.

In summary, we strongly believe that few, simple, and banal actions can be of great help and support to countering the difficult ongoing situation. Moreover, in the context of the COVID-19 pandemic, a transition from face-to-face clinics to multidisciplinary telemedicine care team could further protect CF patient from the risk of SARS-CoV-2 infection, preserving the CF care model.

\section{AUTHOR CONTRIBUTIONS}

SL developed the original idea and the final revision. SM, GP, MP, EM, DA, and NR wrote the manuscript. SM and GP revised firstly the manuscript and contributed to English revision and references update. MP, EM, DA, and NR made the final analysis and critical revision of the manuscript. All authors read and approved the final manuscript.

13. Blackwell TS, Stecenko AA, Christman JW. Dysregulated NFkappaB activation in cystic fibrosis: evidence for a primary inflammatory disorder. Am J Physiol Lung Cell Mol Physiol. (2001) 281:L69-70. doi: 10.1152/ajplung.2001.281.1.L69

14. Wark PA, Tooze M, Cheese L, Whitehead B, Gibson PG, Wark KF, et al. Viral infections trigger exacerbations of cystic fibrosis in adults and children. Eur Respir J. (2012) 40:510-2. doi: 10.1183/09031936.00202311

15. de Almeida MB, Zerbinati RM, Tateno AF, Oliveira CM, Romão RM, Rodrigues JC, et al. Rhinovirus $\mathrm{C}$ and respiratory exacerbations in children with cystic fibrosis. Emerg Infect Dis. (2010) 16:996-9. doi: 10.3201/eid1606.100063

16. Etherington C, Naseer R, Conway SP, Whitaker P, Denton M, Peckham DG. The role of respiratory viruses in adult patients with cystic fibrosis receiving intravenous antibiotics for a pulmonary exacerbation. J Cystic Fibrosis. (2014) 13:49-55. doi: 10.1016/j.jcf.2013.06.004

17. Ortiz JR, Neuzil KM, Victor JC, Wald A, Aitken ML, Goss CH. Influenzaassociated cystic fibrosis pulmonary exacerbations. Chest. (2010) 137:85260. doi: 10.1378/chest.09-1374

18. Chin M, De Zoysa M, Slinger R, Gaudet E, Vandemheen KL, Chan F, et al. Acute effects of viral respiratory tract infections on sputum bacterial density during CF pulmonary exacerbations. J Cyst Fibros. (2015) 14:4829. doi: 10.1016/j.jcf.2014.11.009

19. Arvind B, Medigeshi GR, Kapil A, Xess I, Singh U, Lodha R, et al. Aetiological agents for pulmonary exacerbations in children with cystic fibrosis: an observational study from a tertiary care centre in northern India. Indian J Med Res. (2020) 151:65-70. doi: 10.4103/ijmr.IJMR_1275_18

20. van Ewijk BE, van der Zalm MM, Wolfs TF, Fleer A, Kimpen JL, Wilbrink B, et al. Prevalence and impact of respiratory viral infections in young children with cystic fibrosis: prospective cohort study. Pediatrics. (2008) 122:11716. doi: 10.1542/peds.2007-3139

21. Burns JL, Emerson J, Kuypers J, Campbell AP, Gibson RL, McNamara S, et al. Respiratory viruses in children with cystic fibrosis: viral detection and clinical findings. Influenza Other Respir Viruses. (2012) 6:21823. doi: 10.1111/j.1750-2659.2011.00292.x

22. Wevers BA, van der Hoek L. Renin-angiotensin system in humancoronavirus pathogenesis. Future Virol. (2010) 5:145-61. doi: 10.2217/fvl.10.4

23. Arkwright PD, Pravica V, Geraghty PJ, Super M, Webb AK, Schwarz M, et al. End-organ dysfunctionin cysticfibrosis: association with angiotensin I converting enzymeand cytokine gene polymorphisms. Am J Respir Crit Care Med. (2003) 167:384-9. doi: 10.1164/rccm.200204-364OC

24. da Silva Filho LV, Zerbinati RM, Tateno AF, Boas LV, de Almeida MB, Levi JE, et al. The differential clinical impact of human coronavirus species in children with cystic fibrosis. J Infect Dis. (2012) 206:384-8. doi: 10.1093/infdis/jis274 
25. Colombo C, Burgel PR, Gartner S, van Koningsbruggen-Rietschel S, Naehrlich L, Sermet-Gaudelus I, et al. Impact of COVID19 on people with cystic fibrosis. Lancet Respir Med. (2020) 8:e35-6. doi: 10.1016/S2213-2600(20)30177-6

26. Balduzzi A, Brivio E, Rovelli A, Rizzari C, Gasperini S, Melzi ML, et al. Lessons after the early management of the COVID-19 outbreak in a pediatric transplant and hemato-oncology center embedded within a COVID19 dedicated hospital in Lombardia, Italy. Estote parati. Bone Marrow Transplant. (2020). doi: 10.1038/s41409-020-0895-4. [Epub ahead of print].

27. Cosgriff R, Ahern S, Bell SC, Brownlee K, Burgel PR, Byrnes C, et al. A multinational report to characterise SARS-CoV-2 infection in people with cystic fibrosis. J Cyst Fibros. (2020). doi: 10.1016/j.jcf.2020.04.012. [Epub ahead of print].

28. Poli P, Timpano S, Goffredo M, Padoan R, Badolato R. Asymptomatic case of Covid-19 in an infant with cystic fibrosis. J Cyst Fibros. (2020). doi: 10.1016/j.jcf.2020.03.017. [Epub ahead of print].

29. Bucher J, Boelle PY, Hubert D, Lebourgeois M, Stremler N, Durieu I, et al. Lessons from a French collaborative case-control study in cystic fibrosis patients during the 2009. A/H1N1 influenza pandemy. BMC Infect Dis. (2016) 16:55. doi: 10.1186/s12879-016-1352-2

30. Ramos KJ, Pilewski JM, Faro A, Marshall BC. Improved Prognosis in Cystic Fibrosis: Consideration for Intensive Care During the COVID-19 Pandemic. Am J Respir Crit Care Med. (2020) 201:1434-5. doi: 10.1164/rccm.202004-0999LE

Conflict of Interest: The authors declare that the research was conducted in the absence of any commercial or financial relationships that could be construed as a potential conflict of interest.

Copyright $\odot 2020$ Manti, Parisi, Papale, Mulè, Aloisio, Rotolo and Leonardi. This is an open-access article distributed under the terms of the Creative Commons Attribution License (CC BY). The use, distribution or reproduction in other forums is permitted, provided the original author(s) and the copyright owner(s) are credited and that the original publication in this journal is cited, in accordance with accepted academic practice. No use, distribution or reproduction is permitted which does not comply with these terms. 